\title{
Structural and Optothermal Properties of Iron Ditelluride Layered Structures in the Framework of the Lattice Compatibility Theory
}

\author{
K. Ben Messaoud, ${ }^{1}$ A. Gantassi, ${ }^{1}$ H. Essaidi, ${ }^{1}$ J. Ouerfelli, ${ }^{1}$ A. Colantoni, ${ }^{2}$ \\ K. Boubaker, ${ }^{1}$ and M. Amlouk ${ }^{1}$ \\ ${ }^{1}$ Faculté des Sciences de Tunis, Unité de Physique des Dispositifs à Semi-conducteurs (UPDS), \\ Tunis El Manar, University 2090 Tunis, Tunisia \\ ${ }^{2}$ Department of Agriculture, Forest, Nature and Energy (DAFNE), University of Tuscia, \\ Via S. Camillo de Lellis snc, 01100 Viterbo, Italy
}

Correspondence should be addressed to K. Boubaker; mmbb11112000@yahoo.fr

Received 6 May 2013; Accepted 13 November 2013; Published 29 January 2014

Academic Editor: Luigi Nicolais

Copyright ( $\odot 2014 \mathrm{~K}$. Ben Messaoud et al. This is an open access article distributed under the Creative Commons Attribution License, which permits unrestricted use, distribution, and reproduction in any medium, provided the original work is properly cited.

\begin{abstract}
This study concerns structural and optothermal properties of iron ditelluride layered structures which were fabricated via a lowcost protocol. The main precursors were $\mathrm{FeCl}_{3} \cdot 6 \mathrm{H}_{2} \mathrm{O}$ and $\mathrm{Fe}_{2} \mathrm{O}_{3}$. After a heat treatment within a tellurium-rich medium at various temperatures $\left(470^{\circ} \mathrm{C}, 500^{\circ} \mathrm{C}\right.$, and $\left.530^{\circ} \mathrm{C}\right)$ during $24 \mathrm{~h}$, classical analyses have been applied to the iron ditelluride layered structures. A good crystalline state with a preferential orientation of the crystallites along (111) direction has been recorded. Moreover, additional opto-thermal investigation and analyses within the framework of the Lattice Compatibility Theory gave plausible explanation for prompt temperature-dependent incorporation of tellurium element inside hematite elaborated matrices.
\end{abstract}

\section{Introduction}

Iron ditelluride is a good representative of crystalline transition metal ditelluride in the $3 \mathrm{~d}$ series. It has been identified as a particularly conductive marcasite containing the narrow 3d band (about $1.1 \mathrm{eV}$ ). Nanocrystalline iron ditelluride has been elaborated by Zhang et al. [1] by a reaction of alkaline aqueous solutions dissolving elemental tellurium and iron (II) complex $\mathrm{Na}_{2}[\mathrm{Fe}(\mathrm{EDTA})]$ at $140^{\circ} \mathrm{C}$ under atmospheric pressure, while Liu et al. [2] used a hydrothermal coreduction method in order to produce room temperature magneticsensitive frohbergite iron ditelluride nanocrystallites [2] using $\mathrm{N}_{2} \mathrm{H}_{4} \cdot \mathrm{H}_{2} \mathrm{O}$ as reductant.

Consecutive attempts of chemical doping induced antiferromagnetic (AFM) $[3,4]$ and orbital orders $[5,6]$ in iron ditelluride compounds, but their applications faced several problems [2-6]. The actual study reports structural and optothermal properties of iron ditelluride layered structures which were developed by a simple process consisting on anneal amorphous iron oxide layers, predeposited by spray pyrolysis of $\mathrm{FeCl}_{3} \cdot 6 \mathrm{H}_{2} \mathrm{O}$ based aqueous solution onto heated pyrex glass substrates, under tellurium atmosphere. This simple and low cost process has been used by Ouertani et al. to obtain $\mathrm{FeS}_{2}$ and $\mathrm{FeSe}_{2}$ and allowed us to obtain $\mathrm{FeTe}_{2}$ marcasite phase thin films $[7,8]$.

\section{Experiment}

An aqueous solution of $\mathrm{FeCl}_{3}-6 \mathrm{H}_{2} \mathrm{O}(0.015 \mathrm{M})$ was prepared and sprayed with a gas vector $\left(\mathrm{N}_{2}\right)$ on glass substrates, which were placed on a hotplate heated at $623 \mathrm{~K} .50 \mathrm{~mL}$ of the solution was sprayed on the heated glass substrates, by means of a nozzle allowing a jet flow rate of $4 \mathrm{~mL} / \mathrm{min}$. The height distance between the nozzle and the substrate is about $30 \mathrm{~cm}$ and the $\mathrm{N}_{2}$ flow is about $4 \mathrm{~L} / \mathrm{min}$. Layers obtained are amorphous and have a red rust color. These as-prepared amorphous iron oxide layers were placed with a small amount 


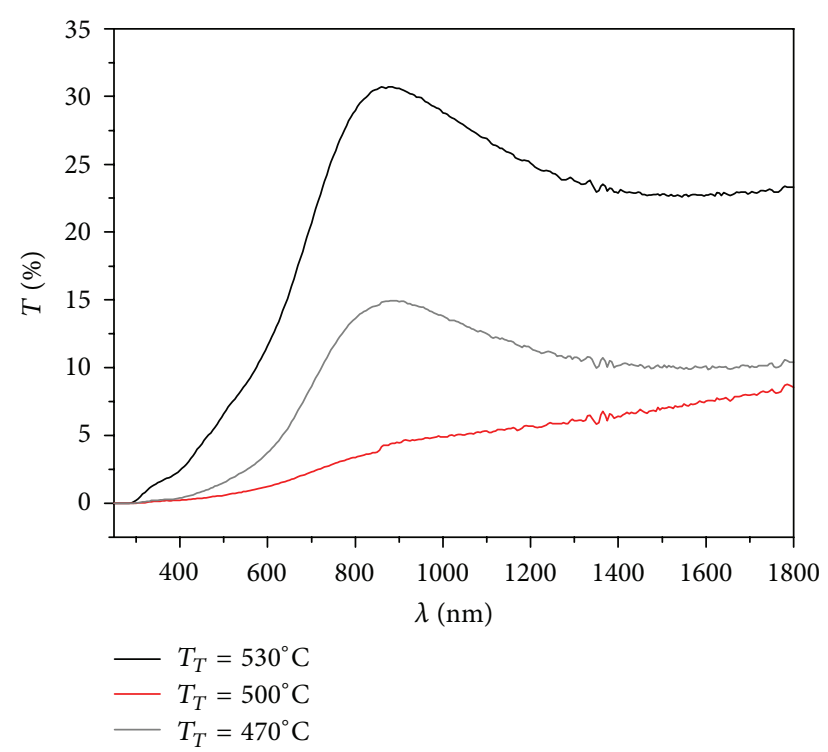

Figure 1: Transmission spectra of the as-grown iron ditelluride layers.

of tellurium in a vacuum-sealed Pyrex tube and subjected to a heat treatment under tellurium atmosphere in an electric tubular oven at different temperatures $\left(470^{\circ} \mathrm{C}, 500^{\circ} \mathrm{C}\right.$, and $530^{\circ} \mathrm{C}$ ) for $24 \mathrm{~h}$.

\section{Optical and Atomic Force Microscopy Analyses}

The optical transmission and reflectance spectra of iron ditelluride films in the wavelength region of 300-1800 $\mathrm{nm}$ are shown in Figures 1 and 2, respectively. All films are a thickness of the order of $200 \mathrm{~nm}$; it can also be seen that the interference fringe patterns are absent in all transmittance and reflectance spectra due to weak multiple reflections at the interface. The films show a high transparency within the visible range with an average transmittance lying between $78-88 \%$. This may be due to the thickness of the films. Consecutively, band gap, refractive index, and extinction coefficient of films have been obtained by fitting from the transmittance spectra of the thin films in the spectral domain varying from 300 to $1800 \mathrm{~nm}$. The model details have been calculated using optical experimental measurements and the method of Bathe and Patil [9] and Belgacem and R. Bennaceur [10]. Spectra patterns confirm the records of Si et al. [11] and Nie et al. [12], who stated that for deposition temperatures beyond $500^{\circ} \mathrm{C}$, the rhombohedral phase of the oxide $\mathrm{Fe}_{2} \mathrm{O}_{3}$ appears and prevents the substitution of oxygen by tellurium.

On the other hand, AFM analyses have been applied to investigate the topography of the $\mathrm{FeTe}_{2}$ thin films. Root mean square surface roughness value was determined on an area of $3 \mu \mathrm{m} \times 3 \mu \mathrm{m}$ for all samples. Figure 3 shows AFM surface morphologies of iron telluride films synthesized at different temperatures. The analysis results are presented in Table 1; indeed the aspects of the explored layers areas show that the

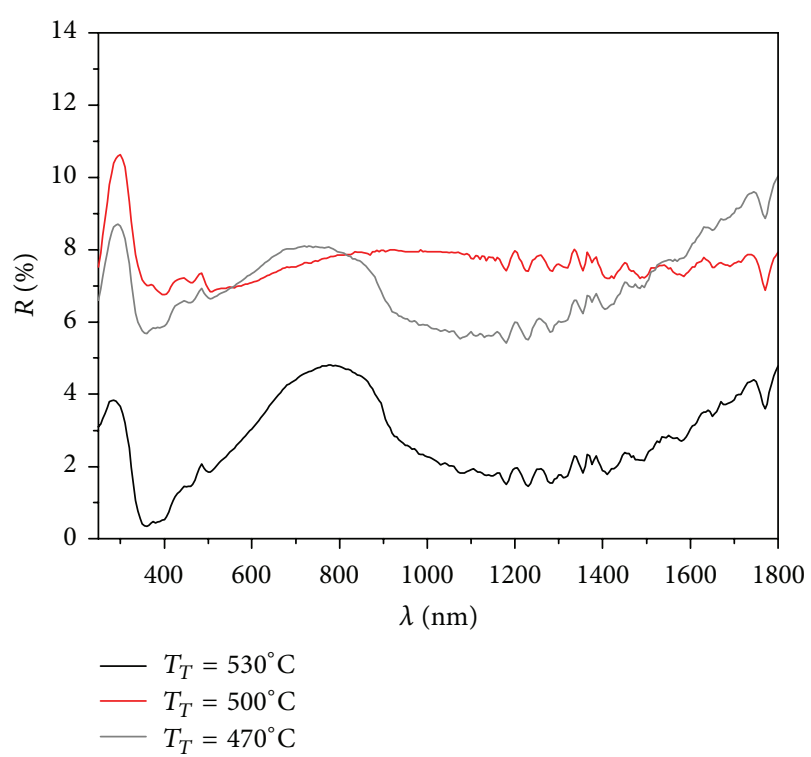

FIGURE 2: Reflectance spectra of the as-grown iron ditelluride layers.

optimized layer, elaborated at $500^{\circ} \mathrm{C}$, has the highest values of rms and average height.

\section{Updated Analyses}

4.1. Optothermal Investigation. The effective absorptivity $\widehat{\alpha}[13,14]$ is the mean normalized absorbance weighted by $I(\widetilde{\lambda})_{\mathrm{AM} 1.5}$, the solar standard irradiance is

$$
\begin{gathered}
\widehat{\alpha}=\frac{\int_{0}^{1} I(\tilde{\lambda})_{\mathrm{AM} 1.5} \times \alpha(\tilde{\lambda}) d \tilde{\lambda}}{\int_{0}^{1} I(\tilde{\lambda})_{\mathrm{AM} 1.5} d \tilde{\lambda}}, \\
\lambda \in\left[\lambda_{\text {min }}, \lambda_{\text {max }}\right] \Longleftrightarrow \tilde{\lambda} \in[0,1], \\
\lambda_{\text {min }}=300.0 \mathrm{~nm} ; \quad \lambda_{\max }=1800.0 \mathrm{~nm},
\end{gathered}
$$

where $I(\widetilde{\lambda})_{\mathrm{AM} 1.5}$ is the Reference Solar Spectral Irradiance, fitted using the Boubaker Polynomials Expansion Scheme BPES [15-35]: $I(\tilde{\lambda})=\left[\left(1 / 2 N_{0}\right) \sum_{n=1}^{N_{0}} \theta_{n} \cdot B_{4 n}\left(\tilde{\lambda} \times \beta_{n}\right)\right]$, where $\beta_{n}$ are the Boubaker polynomials [18-29] $B_{4 n}$ minimal positive roots, $\theta_{n}$ are given coefficients, $N_{0}$ is a given integer, $\alpha(\widetilde{\lambda})$ is the normalized absorbance spectrum, and $\tilde{\lambda}$ is the normalized wavelength. The normalized absorbance spectrum $\alpha(\widetilde{\lambda})$ is deduced from the BPES by establishing a set of $N$ experimental measured values of the transmittancereflectance vector $\left.\left(T_{i}\left(\widetilde{\lambda}_{i}\right) ; R_{i}\left(\tilde{\lambda}_{i}\right)\right)\right|_{i=1 \cdots N}$ versus the normalized wavelength $\left.\tilde{\lambda}_{i}\right|_{i=1 \cdots N}$. Then the system (2) is set:

$$
\begin{aligned}
& R(\tilde{\lambda})=\left[\frac{1}{2 N_{0}} \sum_{n=1}^{N_{0}} \xi_{n} \times B_{4 n}\left(\tilde{\lambda} \times \beta_{n}\right)\right], \\
& T(\tilde{\lambda})=\left[\frac{1}{2 N_{0}} \sum_{n=1}^{N_{0}} \xi_{n}^{\prime} \times B_{4 n}\left(\tilde{\lambda} \times \beta_{n}\right)\right],
\end{aligned}
$$




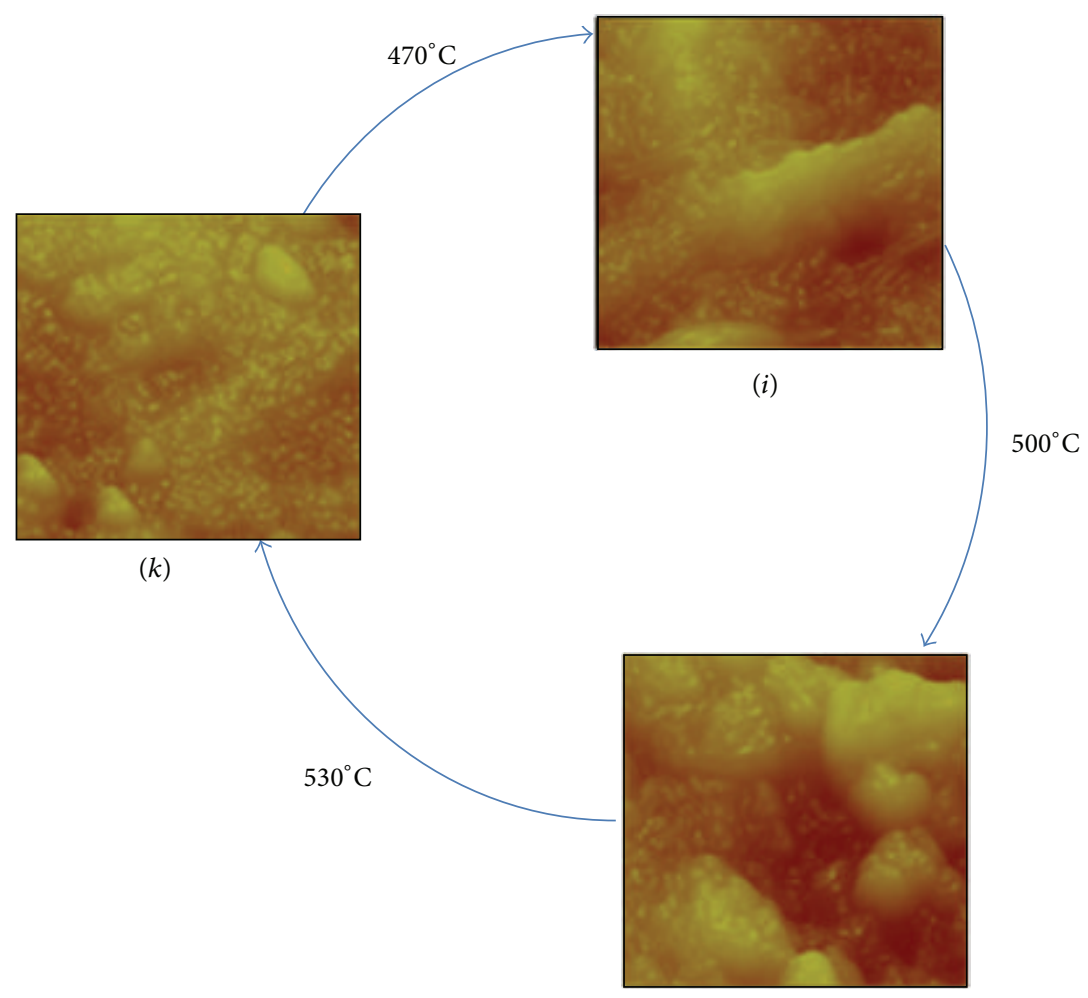

$(j)$

FIGURE 3: 3d AFM surface images of iron telluride films $\left(470^{\circ} \mathrm{C}(i), 500^{\circ} \mathrm{C}(j)\right.$, and $\left.530^{\circ} \mathrm{C}(k)\right)$.

TABLE 1: Layers mean surface roughness and average height versus substrate temperature.

\begin{tabular}{lccr}
\hline & $470^{\circ} \mathrm{C}$ & $500^{\circ} \mathrm{C}$ & $530^{\circ} \mathrm{C}$ \\
\hline rms $(\mathrm{nm})$ & $41.188( \pm 5 \%)$ & $50.018( \pm 5 \%)$ & $30.335( \pm 5 \%)$ \\
Average height $(\mathrm{nm})$ & $277.35( \pm 4 \%)$ & $282.30( \pm 4 \%)$ & $208.97( \pm 4 \%)$ \\
\hline
\end{tabular}

where $\beta_{n}$ are the $4 n$-Boubaker polynomials $B_{4 n}$ minimal positive roots [36-41], $N_{0}$ is a given integer, and $\xi_{n}$ and $\xi_{n}^{\prime}$ are coefficients determined through the Boubaker Polynomials Expansion Scheme BPES.

The normalized absorbance spectrum $\alpha(\widetilde{\lambda})$ is deuced from the relation:

$$
\alpha(\widetilde{\lambda})=\frac{1}{d \sqrt[4]{2}} \cdot \sqrt[4]{\left(\ln \frac{1-R(\tilde{\lambda})}{T(\tilde{\lambda})}\right)^{4}+\left(2 \ln \frac{1-R(\widetilde{\lambda})}{\sqrt{T(\widetilde{\lambda})}}\right)^{4}}
$$

where $d$ is the layer thickness.

The obtained value of normalized absorbance spectrum $\alpha(\tilde{\lambda})$ is a final guide to the determination of the effective absorptivity $\widehat{\alpha}$ through (1).

The Amlouk-Boubaker optothermal expansivity $\Psi_{A B}$ is a thermophysical parameter defined in precedent studies [13, $14]$, as a $3 \mathrm{~d}$ expansion velocity of the transmitted heat inside the material. It is expressed in $\mathrm{m}^{3} \mathrm{~s}^{-1}$, and calculated by

$$
\Psi_{A B}=\frac{D}{\widehat{\alpha}},
$$

where $D$ is the thermal diffusivity and $\widehat{\alpha}$ is the effective absorptivity. Values of the Amlouk-Boubaker optothermal expansivity $\Psi_{A B}$ of the studied films iron telluride films (at $470^{\circ} \mathrm{C}, 500^{\circ} \mathrm{C}$, and $530^{\circ} \mathrm{C}$ ) are gathered in Figure 4.

4.2. Lattice Compatibility Theory LCT Analysis. The Lattice Compatibility Theory, as mentioned in some recent studies [36-38], is based on the interaction of doping-element lattice behavior versus host edifice. Preludes to this theory have been established in the context of analysing Urbach tailing controversial behaviour in some nanocompounds. It was also confirmed by Boubaker [39] on the bases of investigation on some copper-doped compounds. An original formulation of the Lattice Compatibility Theory $[38,39]$ has been established as follows:

"The stability of doping agents inside host structures is favorized by geometrical compatibility, expressed in terms of matching patterns between doping agent intrinsic lattice and those of the host."

In the actually discussed case ( $\mathrm{FeTe}_{2}$ lattice), the nature of the highest occupied bands and the location of holes in 


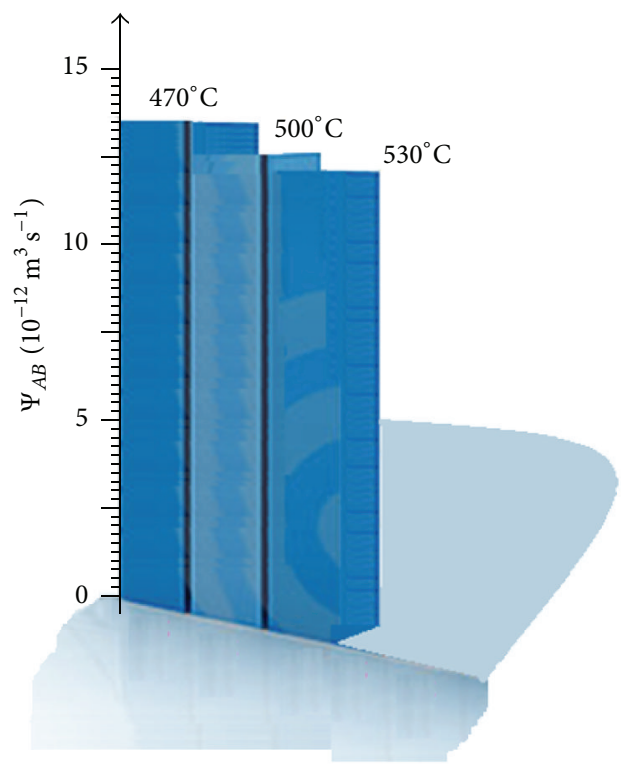

Figure 4: Values of the Amlouk-Boubaker optothermal expansivity $\Psi_{A B}$ for iron telluride films $\left(470^{\circ} \mathrm{C}, 500^{\circ} \mathrm{C}\right.$ and $\left.530^{\circ} \mathrm{C}\right)$.

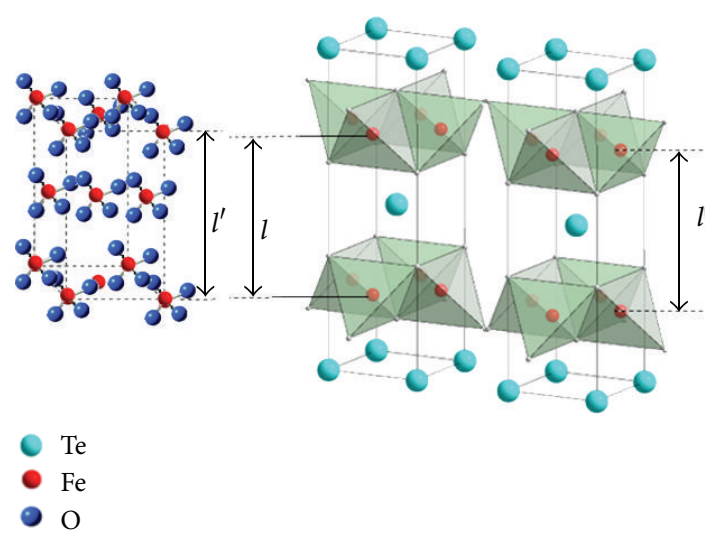

FIGURE 5: $\mathrm{FeTe}_{2}$ lattices elementary configuration.

elemental iron have been demonstrated to be determinant. In this context, fundamental geometrical observations concerning the structure of Te intrinsic lattice (Figure 5) along with the host matrix were interpreted in terms of conventional lattice-linked parameters (i.e., $l$ and $l^{\prime}$ in Figure 5). The similarities between the two structures, as evoked elsewhere $[40,41]$, plea in favor of an easy substitution process between copper and silver ions within ternary structures.

The Lattice Compatibility Theory LCT gives hence an explanation to the incorporation of tellurium in the $\mathrm{FeTe}_{2}$ orthorhombic phase matrix via the substitution of oxygen by tellurium $[42,43]$.

\section{Conclusion}

We have studied the structure and the morphology of iron ditelluride layered structures obtained by a heat treatment within a Te-rich atmosphere of amorphous iron oxide sprayed thin films. Morphological observations show that all films have a relatively perturbed surface state. Additional and original investigations in terms of Amlouk-Boubaker optothermal expansivity $\Psi_{A B}$ showed amorphous iron oxide oxygen substitution patterns. Temperature-dependent alterations have been outlined in the framework of the Lattice Compatibility Theory.

\section{Conflict of Interests}

The authors declare that there is no conflict of interests regarding the publication of this paper.

\section{References}

[1] W. Zhang, Y. Cheng, J. Zhan et al., "Synthesis of nanocrystalline marcasite iron ditelluride $\mathrm{FeTe}_{2}$ in aqueous solution," Materials Science and Engineering B, vol. 79, no. 3, pp. 244-246, 2001.

[2] A. Liu, X. Chen, Z. Zhang, Y. Jiang, and C. Shi, "Selective synthesis and magnetic properties of $\mathrm{FeSe}_{2}$ and $\mathrm{FeTe}_{2}$ nanocrystallites obtained through a hydrothermal co-reduction route," Solid State Communications, vol. 138, no. 10-11, pp. 538-541, 2006.

[3] C. De La Cruz, Q. Huang, J. W. Lynn et al., "Magnetic order close to superconductivity in the iron-based layered $\mathrm{LaO}_{1-x} \mathrm{~F}_{x} \mathrm{FeAs}$ systems," Nature, vol. 453, no. 7197, pp. 899-902, 2008.

[4] W. Bao, Y. Qiu, Q. Huang et al., “Tunable $(\delta \pi, \delta \pi)$-type antiferromagnetic order in $\alpha$-Fe(Te,Se) superconductors," Physical Review Letters, vol. 102, no. 24, Article ID 247001, 2009.

[5] M. Fuglsang Jensen, V. Brouet, E. Papalazarou et al., "Angleresolved photoemission study of the role of nesting and orbital orderings in the antiferromagnetic phase of $\mathrm{BaFe}_{2} \mathrm{As}_{2}$," Physical Review B, vol. 84, no. 1, Article ID 014509, 2011.

[6] T. Shimojima, F. Sakaguchi, K. Ishizaka et al., "Orbitalindependent superconducting gaps in iron pnictides," Science, vol. 332, no. 6029, pp. 564-567, 2011.

[7] Y. Mizuguchi, F. Tomioka, S. Tsuda, T. Yamaguchi, and Y. Takano, "FeTe as a candidate material for new iron-based superconductor," Physica C, vol. 469, no. 15-20, pp. 1027-1029, 2009.

[8] B. Ouertani, J. Ouerfelli, M. Saadoun, B. Bessaïs, H. Ezzaouia, and J. C. Bernède, "Transformation of amorphous iron oxide thin films predeposited by spray pyrolysis into a single $\mathrm{FeSe}_{2}$ phase by selenisation," Solar Energy Materials and Solar Cells, vol. 87, pp. 501-511, 2005.

[9] S. R. Bathe and P. S. Patil, "Electrochromic characteristics of fibrous reticulated $\mathrm{WO}_{3}$ thin films prepared by pulsed spray pyrolysis technique," Solar Energy Materials and Solar Cells, vol. 91, no. 12, pp. 1097-1101, 2007.

[10] S. Belgacem and R. Bennaceur, "Propriétés optiques des couches minces de $\mathrm{SnO}_{2}$ et $\mathrm{CuInS}_{2}$ airless spray," Revue de Physique Appliquée, vol. 25, p. 1245, 1990.

[11] W. Si, Q. Jie, L. Wu et al., "Superconductivity in epitaxial thin films of $\mathrm{Fe}_{1.08}$ Te: $\mathrm{O}_{x}$ ”, Physical Review B, vol. 81, no. 9, Article ID 092506, 2010.

[12] Y. F. Nie, D. Telesca, J. I. Budnick, B. Sinkovic, and B. O. Wells, "Superconductivity induced in iron telluride films by low-temperature oxygen incorporation," Physical Review B, vol. 82, no. 2, Article ID 020508, 2010. 
[13] A. Amlouk, K. Boubaker, and M. Amlouk, " $\mathrm{SnO}_{2}$ thin films morphological and optical properties in terms of the Boubaker Polynomials Expansion Scheme BPES-related Opto-Thermal Expansivity $\Psi_{A B}$, Journal of Alloys and Compounds, vol. 490, no. 1-2, pp. 602-604, 2010.

[14] A. Amlouk, K. Boubaker, M. Amlouk, and M. Bouhafs, "Study of ytterbium doping effects on structural, mechanical and opto-thermal properties of sprayed $\mathrm{ZnO}$ thin films using the Boubaker Polynomials Expansion Scheme (BPES)," Journal of Alloys and Compounds, vol. 485, no. 1-2, pp. 887-891, 2009.

[15] M. Agida and A. S. Kumar, "A Boubaker polynomials expansion scheme solution to random Love's equation in the case of a rational Kernel," Electronic Journal of Theoretical Physics, vol. 7, no. 24, pp. 319-326, 2010.

[16] A. Yildirim, S. T. Mohyud-Din, and D. H. Zhang, "Analytical solutions to the pulsed Klein-Gordon equation using Modified Variational Iteration Method (MVIM) and Boubaker Polynomials Expansion Scheme (BPES)," Computers and Mathematics with Applications, vol. 59, no. 8, pp. 2473-2477, 2010.

[17] J. Ghanouchi, H. Labiadh, and K. Boubaker, "An attempt to solve the heat transfer equation in a model of pyrolysis spray using 4q-order m-boubaker polynomials," International Journal of Heat and Technology, vol. 26, no. 1, pp. 49-53, 2008.

[18] S. Slama, J. Bessrour, K. Boubaker, and M. Bouhafs, "A dynamical model for investigation of $\mathrm{A}_{3}$ point maximal spatial evolution during resistance spot welding using Boubaker polynomials," The European Physical Journal Applied Physics, vol. 44, no. 3, pp. 317-322, 2008.

[19] S. Slama, M. Bouhafs, and K. B. Ben Mahmoud, "A boubaker polynomials solution to heat equation for monitoring $A_{3}$ point evolution during resistance spot welding," International Journal of Heat and Technology, vol. 26, no. 2, pp. 141-145, 2008.

[20] S. Lazzez, K. B. Ben Mahmoud, S. Abroug, F. Saadallah, and M. Amlouk, "A Boubaker polynomials expansion scheme (BPES)related protocol for measuring sprayed thin films thermal characteristics," Current Applied Physics, vol. 9, no. 5, pp. 11291133, 2009.

[21] T. Ghrib, K. Boubaker, and M. Bouhafs, "Investigation of thermal diffusivitymicrohardness correlation extended to surfacenitrured steel using Boubaker polynomials expansion," Modern Physics Letters B, vol. 22, no. 29, pp. 2893-2907, 2008.

[22] S. Fridjine, K. B. Ben Mahmoud, M. Amlouk, and M. Bouhafs, "A study of sulfur/selenium substitution effects on physical and mechanical properties of vacuum-grown $\mathrm{ZnS}_{1-x} \mathrm{Sex}$ compounds using Boubaker polynomials expansion scheme (BPES)," Journal of Alloys and Compounds, vol. 479, no. 1-2, pp. 457-461, 2009.

[23] C. Khélia, K. Boubaker, T. Ben Nasrallah, M. Amlouk, and S. Belgacem, "Morphological and thermal properties of $\beta$-SnS2 sprayed thin films using Boubaker polynomials expansion," Journal of Alloys and Compounds, vol. 477, no. 1-2, pp. 461-467, 2009.

[24] K. B. Ben Mahmoud and M. Amlouk, "The 3D AmloukBoubaker expansivity-energy gap-Vickers hardness abacus: a new tool for optimizing semiconductor thin film materials," Materials Letters, vol. 63, no. 12, pp. 991-994, 2009.

[25] M. Dada, O. B. Awojoyogbe, and K. Boubaker, "Heat transfer spray model: an improved theoretical thermal time-response to uniform layers deposit using Bessel and Boubaker polynomials," Current Applied Physics, vol. 9, no. 3, pp. 622-624, 2009.

[26] S. A. H. A. E. Tabatabaei, T. Zhao, O. B. Awojoyogbe, and F. O. Moses, "Cut-off cooling velocity profiling inside a keyhole model using the Boubaker polynomials expansion scheme," International Journal of Heat and Mass Transfer, vol. 45, no. 10, pp. 1247-1251, 2009.

[27] A. Belhadj, J. Bessrour, M. Bouhafs, and L. Barrallier, "Experimental and theoretical cooling velocity profile inside laser welded metals using keyhole approximation and Boubaker polynomials expansion," Journal of Thermal Analysis and Calorimetry, vol. 97, no. 3, pp. 911-915, 2009.

[28] A. Belhadj, O. F. Onyango, and N. Rozibaeva, "Boubaker polynomials expansion scheme-related heat transfer investigation inside keyhole model," Journal of Thermophysics and Heat Transfer, vol. 23, no. 3, pp. 639-640, 2009.

[29] P. Barry and A. Hennessy, "Meixner-type results for Riordan arrays and associated integer sequences," Journal of Integer Sequences, vol. 13, no. 9, pp. 1-34, 2010.

[30] A. S. Kumar, "An analytical solution to applied mathematicsrelated Love's equation using the Boubaker polynomials expansion scheme," Journal of the Franklin Institute, vol. 347, no. 9, pp. 1755-1761, 2010.

[31] S. Fridjine and M. Amlouk, "A new parameter: an abacus for optimizing PVT hybrid solar device functional materials using the boubaker polynomials expansion scheme," Modern Physics Letters B, vol. 23, no. 17, pp. 2179-2191, 2009.

[32] M. Benhaliliba, C. E. Benouis, K. Boubaker, M. Amlouk, and A. Amlouk, "A new guide to thermally optimized doped oxides monolayer spray-grown solar cells: the amlouk-boubaker optothermal expansivity $\psi \mathrm{ab}$," in Solar Cells-New Aspects and Solutions, L. A. Kosyachenko, Ed., pp. 27-41, InTech, 2011.

[33] A. Milgram, "The stability of the Boubaker polynomials expansion scheme (BPES)-based solution to Lotka-Volterra problem," Journal of Theoretical Biology, vol. 271, no. 1, pp. 157-158, 2011.

[34] H. Rahmanov, "A solution to the non linear Korteweg-De-Vries equation in the particular case dispersion-adsorption problem in porous media using the spectral Boubaker Polynomials Expansion Scheme (BPES)," Studies in Nonlinear Sciences, vol. 2, no. 1, pp. 46-49, 2011.

[35] I. Prigogine, The Molecular Theory of Solutions, North-Holland, Amsterdam, The Netherlands, 1957.

[36] J. O. Hirschfelder, C. F. Curtiss, and R. B. Bird, Molecular Theory of Gases and Liquids, John Wiley \& Sons, New York, NY, USA, 1954.

[37] J. Park and H. Kim, "A new equation of state based on hole theory," Fluid Phase Equilibria, vol. 144, no. 1-2, pp. 77-86, 1998.

[38] K. Boubaker, "Preludes to the lattice compatibility theory LCT: urbach tailing controversial behavior in some nanocompounds," ISRN Nanomaterials, vol. 2012, Article ID 173198, 4 pages, 2012.

[39] K. Boubaker, "The lattice compatibility theory: arguments for recorded I-III- $\mathrm{O}_{2}$ ternary oxide ceramics instability at low temperatures beside ternary telluride and sulphide ceramics," Journal of Ceramics, vol. 2013, Article ID 734015, 6 pages, 2013.

[40] K. Boubaker, M. Amlouk, Y. Louartassi, and H. Labiadh, "About unexpected crystallization behaviors of some ternary oxide and sulfide ceramics within lattice compatibility theory LCT framework," Journal of the Australian Ceramics Society, vol. 49, no. 1, pp. 115-117, 2013.

[41] P. Petkova and K. Boubaker, "The Lattice Compatibility Theory (LCT): an attempt to explain Urbach tailing patterns in copperdoped bismuth sillenites (BSO) and germanates (BGO)," Journal of Alloys and Compounds, vol. 546, pp. 176-179, 2013. 
[42] K. R. Murali and B. Jayasutha, "Properties of CdTe films brush plated on high temperature substrates," Materials Science in Semiconductor Processing, vol. 10, no. 1, pp. 36-40, 2007.

[43] Y. F. Nie, D. Telesca, J. I. Budnick, B. Sinkovic, R. Ramprasad, and B. O. Wells, "Superconductivity and properties of $\mathrm{FeTeO}_{x}$ films," Journal of Physics and Chemistry of Solids, vol. 72, no. 5, pp. 426-429, 2011. 

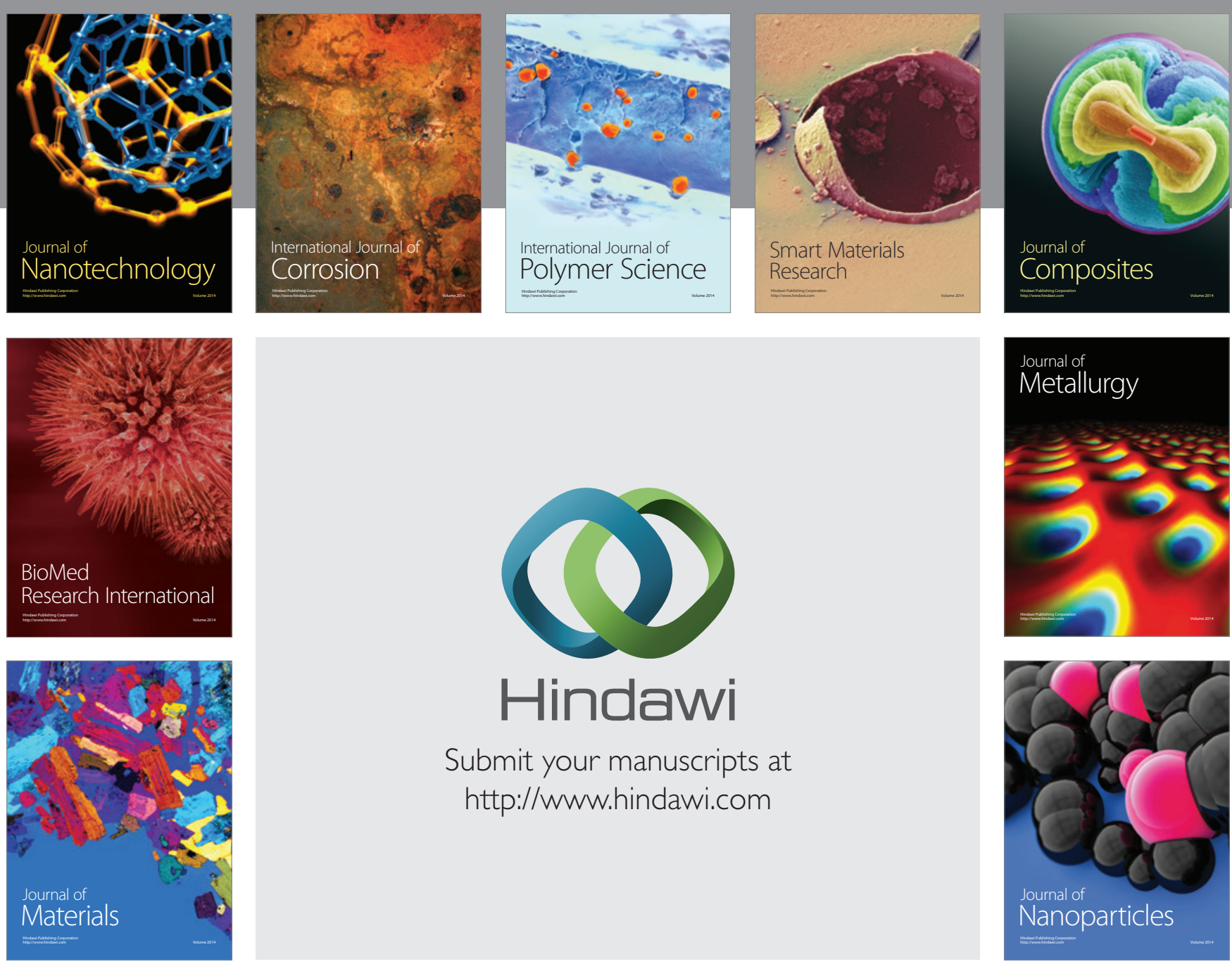

Submit your manuscripts at http://www.hindawi.com
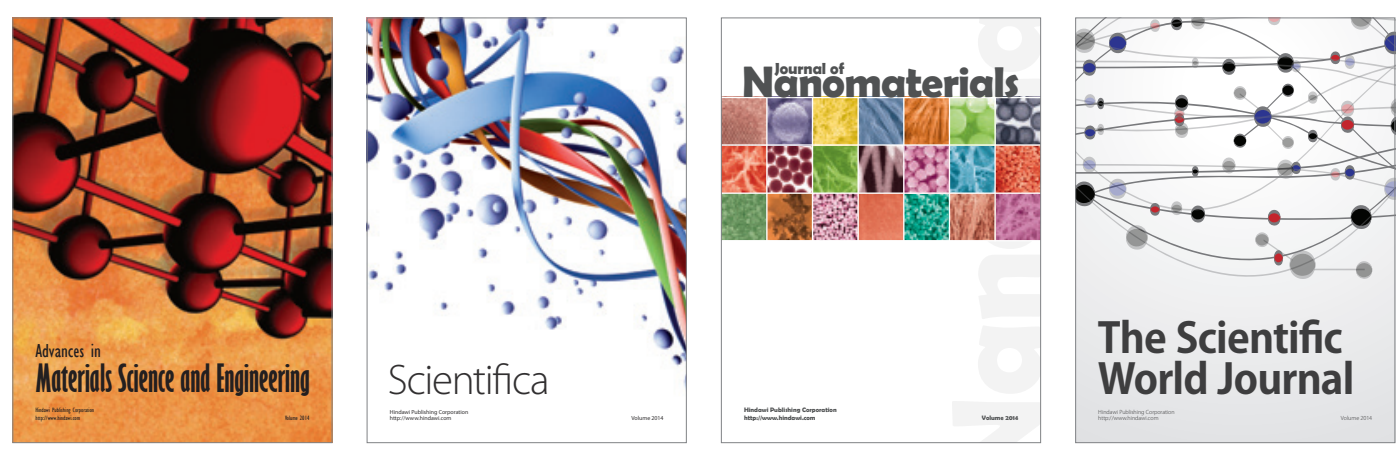

\section{The Scientific World Journal}
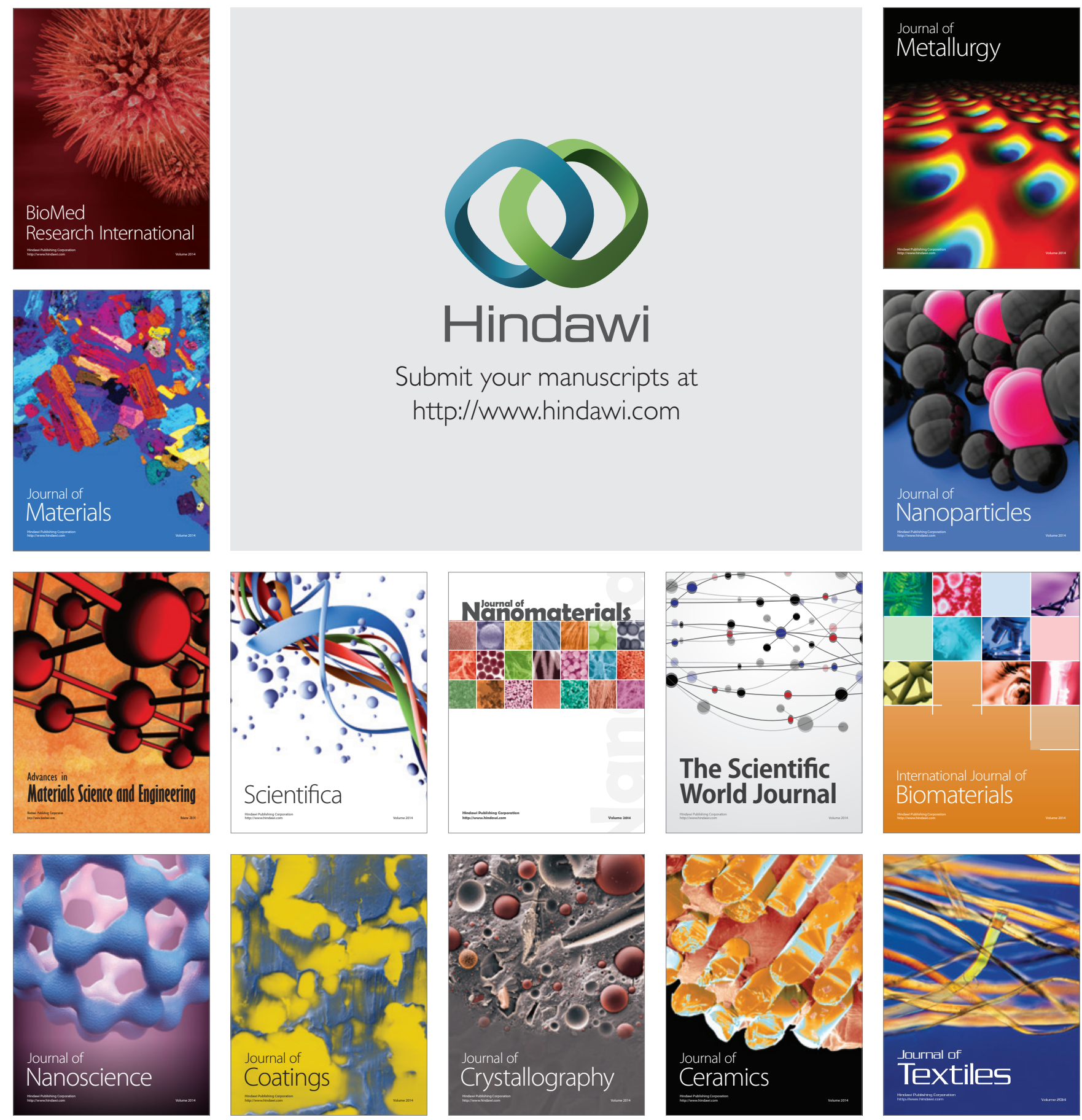